\title{
Abordagem citogenética e molecular em material de abortos espontâneos
}

\author{
Cytogenetic and molecular evaluation of spontaneous abortion samples
}

\author{
Andréa Cristina de Moraes ${ }^{1}$, Antônio Fernandes Moron², Elza Midori Hashimoto³, \\ Ismael Dale Cotrin Guerreiro da Silva ${ }^{4}$, Maria Regina Torloni ${ }^{5}$, \\ Márcia Marcelino de Souza ${ }^{6}$, Francy Reis da Silva Patrício ${ }^{7}$
}

\section{RESUMO}

Objetivos: avaliar o desempenho da citogenética e das técnicas de hibridização in situ fluorescente (FISH) e reação em cadeia da polimerase (PCR) no estudo das aneuploidias cromossômicas numéricas e na determinação do sexo fetal em amostras de abortos espontâneos. Métodos: duzentos e dezenove amostras de produtos de abortos espontâneos foram submetidas a estudo citogenético. Deste total, 40 amostras foram também submetidas à técnica de PCR-nested para a determinação do sexo fetal: 32 foram selecionadas devido à falha de crescimento no estudo citogenético e oito foram escolhidas ao acaso. Vinte amostras foram selecionadas para detecção de aneuploidias cromossômicas pela técnica de FISH, utilizando-se sondas para os cromossomos 13, 18, 21, X e Y: 13 casos foram submetidos a FISH devido à falha de crescimento no estudo citogenético e sete foram escolhidos ao acaso. Foi calculada a taxa de sucesso (obtenção de cariótipo) de cada técnica. Para comparação das taxas de sucesso foi utilizado o teste de $\chi^{2}$, sendo considerados significantes resultados com $\mathrm{p}<0,05$. Foi avaliado o índice de acerto entre os resultados das amostras submetidas a mais de um exame, tomando-se como padrão-ouro o resultado do estudo citogenético. Resultados: houve crescimento celular em $84,9 \%$ das amostras submetidas a análise citogenética. Em 51,1\% dos casos foram encontradas alterações cromossômicas: $65,2 \%$ trissomias, $17,9 \%$ triploidias, 9,4\% tetraploidias, 4,2\% monossomia do cromossomo X e 1,1\% trissomia dupla, tetrassomia e alteração estrutural. A trissomia mais freqüente foi a do cromossomo 16 (39\%). FISH e PCR tiveram taxa de sucesso de 90\%, não diferindo significativamente do exame citogenético. Em todos os casos submetidos a mais de um exame os resultados foram concordantes. Nas amostras com falha de crescimento celular no exame citogenético e submetidas a outra técnica, a PCR obteve sucesso em 87,5\% e a FISH em 84,6\%. Conclusão: o estudo citogenético de restos ovulares de abortamentos espontâneos teve elevada taxa de sucesso e evidenciou anomalias cromossômicas em mais da metade dos casos. As técnicas de biologia molecular (PCR-nested e FISH) complementaram o estudo citogenético e permitiram a obtenção de resultados seguros na detecção de alterações cromossômicas numéricas e na determinação do sexo fetal.

PALAVRAS-CHAVE: Aborto espontâneo/genética; Citogenética/métodos; Fluorescência em hibridização in situ; Reação em cadeia da polimerase

\section{ABSTRACT}

Purpose: to evaluate the performance of cytogenetic analysis, fluorescent in situ hybridization (FISH) and polymerase chain reaction (PCR) in the study of numerical chromosomal anomalies and in fetal sex determination of spontaneous abortion material. Methods: cytogenetic analysis was performed on 219 spontaneous abortion specimens. Forty of these cases were also submitted to fetal sex determination using nested-PCR. Thirty-two of these cases were selected due to failed cytogenetic culture and the other eight were selected randomly. Twenty samples were submitted to the FISH technique, using probes for chromosomes 13, 18,21, X and $\mathrm{Y}$. Thirteen of these samples were selected due to failed cytogenetic culture and the other seven were randomly selected. The success rates of each technique were compared using the $\chi^{2}$ test and an

1 Bióloga, Diretora do Centro Paulista de Medicina Fetal (Laboratório de Citogenética), São Paulo; Aluna de pós-graduação do Departamento de Patologia da Universidade Federal de São Paulo - UNIFESP - São Paulo (SP) - Brasil.

2 Médico, Diretor do Centro Paulista de Medicina Fetal, São Paulo, Chefe da Disciplina de Medicina Fetal, Universidade Federal de São Paulo - UNIFESP - São Paulo (SP) - Brasil.

3 Bióloga, Diretora do Centro Paulista de Medicina Fetal (Laboratório de Citogenética), São Paulo

4 Médico, Laboratório de Biologia Molecular do Departamento de Ginecologia da Universidade Federal de São Paulo - UNIFESP - São Paulo (SP) - Brasil.

5 Médica, Disciplina de Medicina Fetal da Universidade Federal de São Paulo - UNIFESP - São Paulo (SP) - Brasil.

6 Médica, Departamento de Patologia da Universidade Federal de São Paulo - UNIFESP - São Paulo (SP) - Brasil.

7 Médica, Professor Adjunto do Departamento de Patologia da Universidade Federal de São Paulo - UNIFESP - São Paulo (SP) - Brasil.

Correspondência: Andréa Cristina de Moraes

Rua: Estado de Israel, 847, ap 83 - Vila Clementino - 04022-002 - São Paulo-SP - Telefone: 11- 5084-7443 / $5572-4449$ ramal 104/ 9599 -1861 e-mail: deagen@uol.com.br 
established $\mathrm{p}<0.05$ level of significance. The results of samples submitted to more than one test were evaluated for accuracy, using the cytogenetic result as the gold standard. Results: cytogenetic analysis was successful in $84.9 \%$ of the samples and in $51.1 \%$ of them the results were abnormal: $65.2 \%$ trisomy, $17.9 \%$ triploidy, $9.4 \%$ tetraploidy, $4.2 \%$ chromosome X monosomy, and $1.1 \%$ each for double trisomy, tetrasomy and structural abnormality. The most frequent trisomy was that of chromosome $16(39 \%)$. The success rate of FISH and PCR techniques (90\%) did nod differ significantly from the cytogenetic analysis. In all cases submitted to more than one test, the results were identical to those obtained through cytogenetic analysis. Samples that failed to grow on cytogenetic test and that were submitted to other techniques of molecular biology had a success rate of 87.5 and $84.6 \%$ for PCR and FISH, respectively. Conclusion: cytogenetic analysis of spontaneous abortions had a high success rate and chromosomal anomalies were identified in over half of the cases. Molecular biology techniques (PCR and FISH) complemented the cytogenetic study and proved to be reliable in the detection of numerical chromosomal anomalies and in fetal sex determination.

KEYWORDS: Abortion, spontaneous/genetics; Cytogenetics/methods; In situ hybridization, fluorescence; Polymerase chain reaction

\section{Introdução}

Nos últimos 45 anos a citogenética humana vem despontando como importante método no diagnóstico de diversas doenças e também como mais um recurso de medicina preventiva, graças ao surgimento do aconselhamento genético. Estima-se que as anomalias cromossômicas sejam responsáveis por mais de 60 sindromes identificáveis, sendo mais comuns que todos os distúrbios monogênicos juntos ${ }^{1}$. As anomalias cromossômicas afetam $0,7 \%$ dos nascidos vivos, $2 \%$ das gestações em mulheres com mais de 35 anos e estão presentes em $50 \%$ dos abortos espontâneos do primeiro trimestre ${ }^{1}$.

O abortamento espontâneo é fenômeno comum que compromete 15 a $20 \%$ das gestações ${ }^{2}$. Estima-se que existam anomalias cromossômicas em aproximadamente metade das perdas fetais ocorridas entre a $8^{\mathrm{a}}$ e a $15^{\mathrm{a}}$ semana $^{3}$.

Até a década de 60 , a investigação das perdas fetais limitava-se ao estudo clínico e anatomopatológico. $\mathrm{O}$ advento da citogenética possibilitou a investigação de possiveis anomalias cromossômicas nesses casos.

Graças ao método de cultura direta desenvolvido por Simoni et al. $(1983)^{4}$, o estudo citogenético passou a ser realizado rotineiramente pela maioria dos laboratórios de citogenética, porém o resultado demorava 30 a 40 dias. O surgimento da cultura semidireta em 1990, uma modificação do método original, reduziu os custos do exame e o prazo para obtenção de resultados, atualmente disponiveis em 24 a 48 horas.

Diversos estudos ${ }^{5,6}$ apontam a importância do estudo citogenético dos restos ovulares e sugerem que antes de os ginecologistas submeterem um casal que teve abortos a uma série de exames complementares sofisticados para investigar possiveis causas de perdas, seria fundamental analisar o cariótipo dos abortos em questão.
A literatura reforça a importância do estudo citogenético em material de restos ovulares, evidenciando anomalias cromossômicas em metade dos $\operatorname{casos}^{7-9}$. Porém, em até $40 \%$ das culturas de abortos não ocorre crescimento celular, provavelmente devido à degeneração das vilosidades coriônicas ${ }^{10}$. A obtenção de tecido viável é essencial para a análise cromossômica. Portanto, preconiza-se a obtenção da amostra (vilosidade coriônica ou pele fetal) imediatamente após o diagnóstico da morte embrionária ou fetal, não se ultrapassando sete dias dessa data ${ }^{10}$. Infelizmente, nem sempre essas condições ideais existem na prática médica.

Quando ocorre falha de crescimento celular em material de abortamento, é possivel tentar a obtenção do cariótipo por meio de técnicas de biologia molecular. Nos últimos anos, com os avanços do conhecimento e tecnologias nessa área, as técnicas de hibridização in situ fluorescente (FISH) e reação em cadeia da polimerase (PCR)-nested estão sendo utilizadas em associação à análise citogenética no diagnóstico pré-natal e de abortos. Esses procedimentos aumentaram consideravelmente o nivel de sensibilidade na detecção das aberrações cromossômicas, criando-se nova área de estudo denominada "citogenética molecular".

O uso dessas técnicas complementares seria importante especialmente nos casos de falha de crescimento celular em abortamentos com alto risco para cromossomopatias, por exemplo, em casais com antecedentes familiares de aneuploidias ou doenças gênicas ligadas ao $\mathrm{X}$ ou naqueles casos em que o ultra-som obstétrico evidenciou feto hidrópico ou com anomalias estruturais.

Uma segunda vantagem dessas técnicas complementares seria a obtenção de diagnóstico rápido das aberrações cromossômicas numéricas e das doenças ligadas ao sexo. Enquanto o estudo citogenético tradicional requer em média 20 dias para ser concluído, os resultados da FISH e da PCR tornam-se disponíveis em 24 a 48 horas. Apesar 
de teoricamente não existir urgência na obtenção do resultado após um abortamento, a rapidez dos resultados pode auxiliar a reduzir a ansiedade do casal.

Uma desvantagem dos exames de biologia molecular seria seu alto custo, além de não permitirem a detecção de anomalias cromossômicas estruturais ou mosaicismo.

Em nosso meio, apesar de existirem alguns trabalhos a respeito do estudo citogenético de restos ovulares ${ }^{11,12}$, não encontramos publicações relatando o uso de técnicas de biologia molecular no estudo de casos de abortamento.

Movidos pela escassez de dados nacionais, decidimos analisar nossa experiência com o uso das técnicas atualmente disponiveis para análise genética de restos ovulares.

O objetivo deste estudo foi avaliar o desempenho da citogenética, da FISH e da PCR no estudo de restos ovulares de abortos espontâneos. Especificamente, avaliamos a taxa de sucesso de cada um dos três métodos na obtenção de resultados (cariótipo) e seu grau de concordância, nos casos submetidos a mais de um método. Um objetivo secundário foi avaliar a freqüência e a distribuição de alterações cromossômicas em casos de abortamento espontâneo.

\section{Métodos}

Este foi estudo retrospectivo que incluiu todas as amostras consecutivas $(n=219)$ de abortos espontâneos (com idade gestacional de até 20 semanas) provenientes do Hospital São Paulo e da Maternidade Santa Joana e enviadas ao Centro Paulista de Medicina Fetal entre janeiro de 2001 e janeiro de 2002. O trabalho foi aprovado pelo Comitê de Ética da UNIFESP/Hospital São Paulo.

A idade das 219 pacientes variou de 18 a 44 anos, com média de 31,7 anos $( \pm 6,2$ anos, desviopadrão). A idade gestacional média informada foi de 10 semanas $\pm 4,5$ semanas. As 219 amostras foram submetidas ao estudo citogenético e 40 delas foram selecionadas para complementação diagnóstica com biologia molecular (20 por PCR e FISH e 20 só por PCR).

Todos os 40 casos submetidos ao estudo complementar eram de alto risco, apresentando pelo menos um dos seguintes: história de aborto de repetição, história familiar de anomalias cromossômicas ou doenças gênicas ligadas ao X, ou anomalias ultra-sonográficas sugestivas de cromossomopatias.

Todos os casos sem crescimento celular no exame citogenético $(n=33)$ foram submetidos ao estudo complementar, sendo 20 submetidos a PCR e 13 submetidos a FISH e PCR. Entre os casos com crescimento celular no exame citogenético, oito foram selecionados aleatoriamente para serem submetidos também a técnicas moleculares.

Em todos os 219 casos, também foi realizado o estudo histológico dos restos ovulares, a partir de uma segunda amostra do material de aborto fixada em formol. Esta amostra foi processada (média de três lâminas por caso), corada com hematoxilina-eosina e analisada pelo patologista de forma habitual (avaliação histológica de vilosidades, cordão, membranas, trofoblasto, feto ou embrião e alterações adaptativas deciduais), para determinar a provável época de ocorrência do óbito embrionário ${ }^{13}$, dado este que foi utilizado no esclarecimento da possivel causa da falha do estudo citogenético.

\section{Citogenética}

Os restos ovulares foram encaminhados para estudo citogenético em frasco estéril com 10 $\mathrm{mL}$ de soro fisiológico ou meio de cultura 199. O tempo entre a coleta do material e o envio ao laboratório não excedeu 48 horas e durante esse período o material foi mantido refrigerado a $4^{\circ} \mathrm{C}$.

O material de aborto ocorrido entre a $5^{\mathrm{a}}$ e a $13^{a}$ semana gestacional foi inicialmente submetido à cultura semidireta de vilosidade coriônica (cultura de 48 a 92 horas). Caso não ocorresse crescimento celular dentro desse prazo, o material era submetido a cultura prolongada (cultura de 20 a 30 dias). Acima da $14^{\mathrm{a}}$ semana gestacional era sempre realizada a cultura prolongada. Nesta técnica, o material é inicialmente deixado em solução de tripsina por 30 minutos e depois semeado em cultura, obtendo-se o crescimento celular dentro de 20 a 30 dias. Foram analisadas de 10 a 20 metáfases em dois microscópios (BX 40 - Olympus e Aristoplan - Leica Leitz ${ }^{\circledR}$ com objetiva de 100X), sendo a mais representativa capturada para a análise computadorizada pelo sistema Leica Chantal ${ }^{\circledR}$.

\section{FISH}

A técnica de FISH foi desenvolvida de acordo com os trabalhos de Eiben et al. ${ }^{14}$ e Jobanputra et al. ${ }^{15,16}$ e padronizada com algumas modificações do kit da marca Cytocell.

Nos casos sem crescimento celular no estudo citogenético, naqueles com história de abortamento de repetição ou naqueles com suspeita ultra-sonográfica de cromossomopatias, as lâminas foram descoloridas em três séries crescentes de álcoois: 70, 85 e 90\%, e posteriormente iniciouse o pré-tratamento.

Após pré-tratamento, hibridização por 16 a 18 horas com as sondas dos cromossomos 13, 18, $21 \mathrm{X}$ e Y e lavagem das lâminas pós-hibridização, elas foram coradas com $15 \mu \mathrm{L}$ de 4'6'-diamino-2'- 
fenilindol (azul - DAPI) ou iodeto de propídio (PI), cobertas com lamínula e vedadas com esmalte.

A lâmina foi deixada no escuro por 30 minutos antes de ser analisada no microscópio de fluorescência Aristoplan - Leica Leitz ${ }^{\circledR}$, equipado com filtros individuais para FITC (fluorocromo isotiocionato de fluoresceína [480-525 nm], DAPI e PI. Foram examinados de 100 a 150 núcleos e as imagens digitalizadas foram analisadas pelo software Q-FISH da Leica Image ${ }^{\circledR}$.

\section{PCR}

Foi utilizada a técnica de PCR-nested, que possui duas etapas de amplificação, utilizando-se de dois pares de primers por etapa. Foram amplificadas simultaneamente a região homóloga dos cromossomos X e Y para a determinação do sexo fetal. O fragmento do cromossomo $\mathrm{X}$ serviu como controle interno, e o sucesso da amplificação dependeu da amplificação específica do fragmento do cromossomo $\mathrm{Y}^{17}$.

A extração de DNA do material de aborto espontâneo e a técnica de PCR-nested foram padronizadas no Laboratório Experimental de Biologia Molecular do Departamento de Ginecologia da Escola Paulista de Medicina da Universidade Federal de São Paulo. Foi usado o kit de extração Miniprep System da GIBCO, com algumas adaptações.

$\mathrm{Na}$ PCR-nested foram realizadas algumas modificações na ciclagem proposta por Schaaff et al. ${ }^{17}$ e Lim et al. ${ }^{18}$. Enquanto estes autores realizaram 25 ciclos na primeira etapa e 30 ciclos na segunda etapa da PCR, no presente estudo foram utilizados 35 ciclos e 40 ciclos. Esta adaptação foi necessária porque o numero de cópias de seqüência de DNA produzida com 25 a 30 ciclos foi muito pequeno. $\mathrm{O}$ número de ciclos foi gradualmente aumentado e com 35 ciclos na primeira etapa e 40 ciclos na segunda etapa foi possivel visualizar e amplificar os genes estudados. Os primers utilizados para determinação do sexo fetal foram os do gene da amelogenina localizado no cromossomo X (AMGX) para a primeira etapa da PCR-nested, sendo que a seqüência do primer 1-AMG 3 era 5'CTTCCCAGTTTAAGCTCTGATG-3' e do primer 2AMG 4 era 5'-CCTTGCTCATATTATACTTGAC-3'.

$\mathrm{Na}$ segunda etapa foram utilizados os primers 3 e $4^{15}$ do pseudogene da amelogenina localizado no cromossomo Y (AMGY). Suas seqüências eram primer 3-AMG 5: 5'-CTCAGGGAGGTTCCATGA-3' e primer 4-AMG 6: 5'- TGAGAAAACCAGGGTTCC- 3'.

Para visualização do resultado final, foi utilizado gel de agarose $2 \%$, corado com brometo de etídeo, e o produto final da PCR foi aplicado neste gel $(20 \mu \mathrm{L})$. Nos poços das extremidades do gel foram aplicados $7 \mu \mathrm{L}$ do padrão de pares de bases e colocou-se para correr em cuba de eletroforese a aproximadamente 90 volts. O gel foi fotografado pelo sistema $\operatorname{Kodak}^{\circledR}$.

Foram avaliadas as taxas de sucesso (obtenção de cariótipo) e falha (impossibilidade de obtenção de cariótipo) de cada uma das técnicas (citogenética, FISH e PCR). A taxa de sucesso de cada método foi calculada dividindo-se o número de amostras em que foi possivel determinar o cariótipo pelo número total de amostras submetidas ao exame, multiplicando-se o resultado por cem. Diferenças entre as taxas de sucesso dos diversos métodos foram comparadas por meio do teste do $\chi^{2}$, sendo consideradas significantes diferenças com $p<0,05$. Foi também avaliada a concordância dos resultados das amostras submetidas a mais de uma técnica. Foram comparados os resultados das amostras submetidas a mais de um exame, sendo o resultado do estudo citogenético considerado como padrão-ouro.

\section{Resultados}

A Figura 1 apresenta os tipos de exames a que foram submetidas as 219 amostras de restos ovulares de abortos espontâneos. O crescimento celular e conseqüentemente a determinação do cariótipo foi possivel em 186 das 219 amostras submetidas ao exame citogenético, o que representou uma taxa de sucesso deste exame de 84,9\% (186/219). Em todos os 33 casos em que não houve crescimento celular, o estudo anatomopatológico confirmou a retenção do concepto por mais de sete dias após seu óbito. Dentre as 33 amostras sem crescimento, em 1 não havia material suficiente para extração de DNA e as outras 32 foram submetidas a PCR. Houve sucesso (amplificação na PCR) em 28 desses casos, resultando portanto em taxa de sucesso de $87,5 \%(28 / 32)$ nas amostras com falha de crescimento celular no exame citogenético. Treze das 33 amostras sem crescimento no exame citogenético foram também submetidas a FISH e ocorreu hibridização em 11 desses casos. Portanto, a taxa de sucesso da FISH nas amostras com falha de crescimento celular no exame citogenético foi de 84,6\% (11/13).

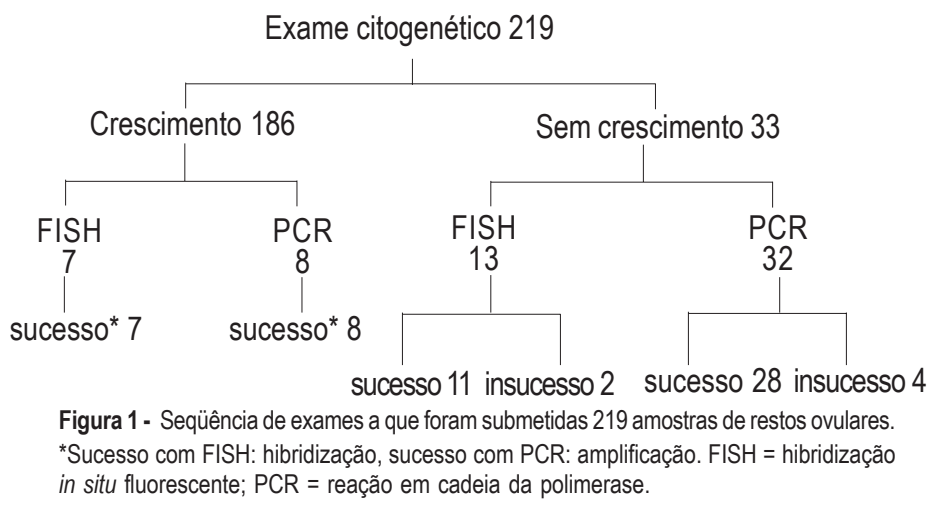


A PCR foi também usada em oito casos em que houve crescimento no estudo citogenético e em todos ocorreu amplificação. Avaliando o desempenho geral da PCR, observamos que das 40 amostras de restos ovulares submetidas ao exame, houve amplificação em 36 , o que resultou em taxa de sucesso total de 90\% (36/40). Nas 36 amostras com amplificação, o sexo foi apontado como feminino (presença de um único fragmento de $323 \mathrm{pb}$ ) em $65 \%$ e masculino (dois fragmentos amplificados de 323 pb e 142 pb) em 35\%. Houve concordância no resultado do sexo fetal nas oito amostras submetidas tanto ao estudo citogenético como à PCR.

A FISH foi também usada em sete casos em que houve crescimento no exame citogenético, e em todos os casos os resultados foram concordantes. Avaliando o desempenho geral da FISH, observamos que dos 20 casos submetidos ao exame, em 18 ocorreu hibridização, resultando portanto em taxa de sucesso geral de $90 \%(18 / 20)$. Nas 18 amostras com hibridização, o cariótipo foi normal em 14 e anormal em quatro: dois casos de trissomias, um de triploidia e um de monossomia do X.

As taxas de sucesso geral dos três métodos, $84,5 \%$ no estudo citogenético, $90 \%$ com FISH e $90 \%$ com PCR (Tabela 1), não apresentaram diferenças estatisticamente significantes $(p=0,41$ e 0,39, comparando FISH e PCR com o estudo citogenético).

Tabela 1 - Desempenho de três métodos na obtenção de cariótipos em material de aborto espontâneo.

\begin{tabular}{|c|c|c|c|}
\hline \multirow[b]{2}{*}{ Método } & \multicolumn{3}{|c|}{ Sucesso* } \\
\hline & $\mathrm{n}$ & $(\%)$ & $p$ \\
\hline Citogenética & $186 / 219$ & $(84,9)$ & - \\
\hline FISH & $18 / 20$ & $(90,0)$ & 0,41 \\
\hline PCR & $36 / 40$ & $(90,0)$ & 0,39 \\
\hline
\end{tabular}

Tabela 2 - Distribuição das alterações cromossômicas encontradas em 95 casos de abortamento com cariótipos anormais no estudo citogenético.

\begin{tabular}{lll}
\hline Tipo de alteração & $\mathbf{n}$ & $\mathbf{( \% )}$ \\
\hline Trissomias & 62 & $65,2^{*}$ \\
Triploidia & 17 & $17,9^{*}$ \\
Tetraploidia & 9 & 9,4 \\
Monossomia X & 4 & 4,2 \\
Trissomia dupla & 1 & 1,1 \\
Tetrassomia 15 & 1 & 1,1 \\
Alteração estrutural & 1 & 1,1 \\
\hline${ }^{*}$ Mostradas na Figura 2. & & \\
\hline
\end{tabular}

Figura 2 - Cariótipos representativos das alterações cromossômicas mais freqüentes nos abortos espontâneos. A: cariótipo representativo de trissomia do cromossomo 16 $(47, \mathrm{XY}+16)$; B: cariótipo representativo de trissomia do cromossomo $22(47, \mathrm{XY},+22) ; \mathrm{C}$ : cariótipo representativo de trissomia do cromossomo 15 (47,XY,+15); D: cariótipo representativo de triploidia $(69, \mathrm{XXY})$.

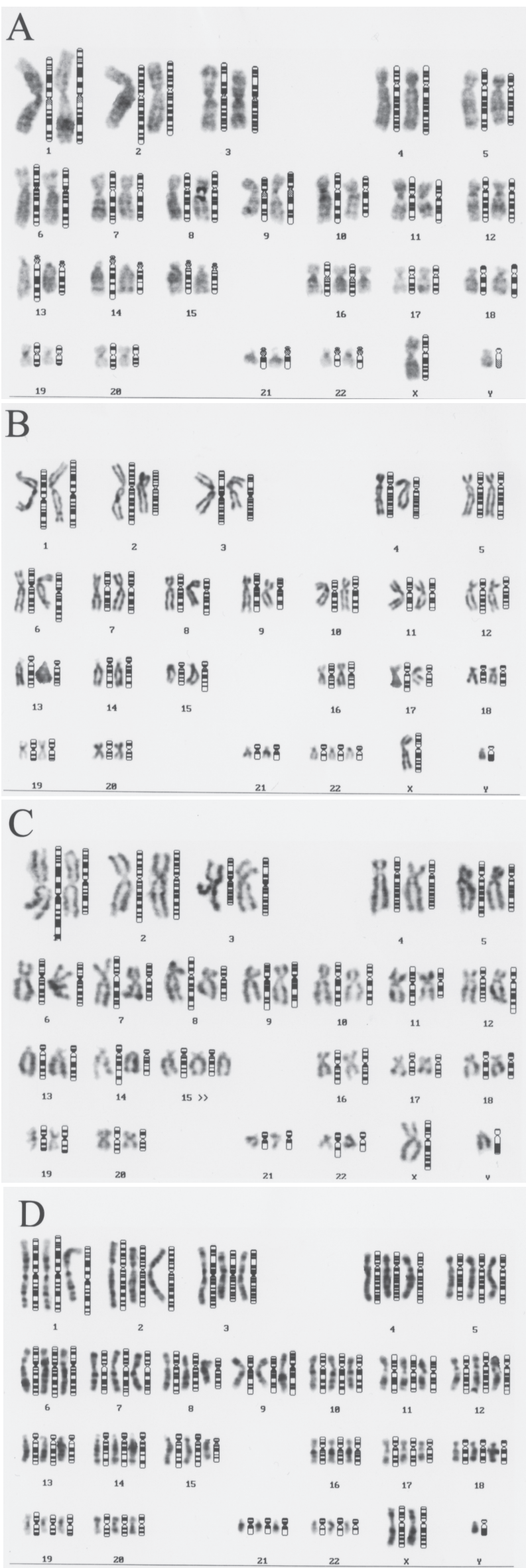


A Tabela 2 apresenta as anomalias cromossômicas específicas detectadas pelo estudo citogenético. As trissomias mais freqüentes foram as do cromossomo 16 (39\%), do $22(21 \%)$ e do 15 (9\%) (Figura 2A, B, C, D).

\section{Discussão}

Utilizando técnica de cultura semidireta de vilosidade coriônica obtivemos ótimo índice de crescimento celular $(84,9 \%)$, comparável aos da literatura, que se situam entre 71 e $80,2 \%{ }^{5}$. Em todos os nossos casos de falha de cultura celular, o exame histológico apontava que o óbito tinha ocorrido há mais de sete dias.

$\mathrm{O}$ estudo citogenético evidenciou que em praticamente metade dos casos de abortamento espontâneo existiam anomalias cromossômicas, sendo $68 \%$ de aneuploidia, 26\% de euploidia e $1 \%$ de alteração estrutural. Kalousek ${ }^{2,5}$ observou aneuploidia em $67 \%$ dos seus casos de aborto e euploidia em $23 \%$.

Diversos trabalhos indicam que as trissomias mais freqüentes em restos ovulares são as dos cromossomos $16,22,13$ e $21^{5,11,19}$. Obtivemos resultados semelhantes, com predomínio da trissomia do cromossomo 16 (39\%), seguida pela do cromossomo 22 (21\%), do 15 (9\%) e dos cromossomos 21,13 e 18 ( $7 \%$ cada uma). A freqüência relativamente baixa de trissomias duplas e tetrassomias obtida em nosso material foi semelhante aos 0,21 a $2,6 \%$ observados por outros autores ${ }^{5,20}$ que estudaram perdas fetais. A incidência de $4,2 \%$ de monossomia do cromossomo X contrasta com a média de $10 \%$ observados por outros autores ${ }^{5,10,11,19}$. Essa diferença pode ser decorrente dos diferentes métodos de cultura (semidireto e longa duração). Nas culturas de longa duração, segundo alguns autores ${ }^{12,19}$, a monossomia do cromossomo $\mathrm{X}$ pode ser mais bem visualizada. Outro fator relevante seria a idade das pacientes. Enquanto a idade média de nossas pacientes com monossomia do $\mathrm{X}$ foi de 33 anos, as de Ohno et al..$^{21}$ tinham 29 anos.

Nas últimas décadas a biologia molecular vem despontando como nova frente de investigação. Esses procedimentos têm mostrado importantes aplicações em especialidades médicas como neurologia, oftalmologia, ginecologia, obstetrícia e medicina fetal. A FISH permite visualizar seqüências específicas de ácidos nucléicos em preparações celulares, material fixado em parafina, tumores, embriões e blastômeros. Por ser método rápido e seguro para detectar aneuploidias, atual- mente a FISH tem sido cada vez mais utilizada como auxiliar da citogenética em diagnóstico prénatal e nos casos de aborto espontâneo. As sondas centroméricas habitualmente utilizadas são as dos cromossomos 13, 18, 21, 16, 22, 15, X e Y ${ }^{14,15}$.

Neste estudo, 13 casos com falha de cultura foram submetidos a FISH e em 11 (84,6\%) a hibridização teve sucesso, permitindo a identificação de anomalias cromossômicas em três amostras. Estes achados evidenciam a importância da utilização dessa técnica complementar nos casos de falha de cultura, especialmente nos casos de alto risco, conforme recomendado na literatu$\mathrm{ra}^{12,14,21}$.

Uma das limitações da FISH é sua incapacidade de detectar anomalias estruturais ou mosaicismo, porém esses achados são bastante raros nos casos de abortamento. Um segundo inconveniente da FISH é seu custo de 75 a 240 dólares, que, somado ao custo do estudo citogenético convencional (30 a 80 dólares), limitaria a sua utilização. Preocupados com esses custos, alguns ${ }^{20}$ sugeriram que a FISH só deveria ser oferecida em casos selecionados de abortos espontâneos, como por exemplo diante de suspeita clínica de mola hidatiforme ${ }^{22}$.

Enquanto utilizamos a FISH em restos ovulares a fresco, a maioria dos trabalhos emprega material incluído em bloco de parafina ${ }^{20,22}$, o que dificulta a comparação dos resultados. Utilizando sondas centroméricas dos cromossomos 1 , $16,18 \mathrm{X}$ e Y em 18 amostras de abortos fixados em parafina, Van Lijnschoten et $a{ }^{20}{ }^{20}$ concluíram que, embora a qualidade do material a fresco seja superior, a FISH pode ser empregada em estudo de material de aborto já processado.

A aplicação da técnica de FISH pode também auxiliar nos casos de mola hidatiforme ${ }^{22}$. Em nosso estudo tivemos um caso com suspeita clínica de mola hidatiforme, cujo resultado anatomopatológico foi mola parcial; a PCR evidenciou sexo masculino e a FISH, três sinais para o cromossomo 18 , dois para o cromossomo X e um para o cromossomo Y. O resultado citogenético confirmou a presença do cariótipo triplóide $(69, \mathrm{XXY})$.

A técnica de PCR tem a vantagem de rapidamente permitir a amplificação enzimática de uma pequena seqüência de DNA e a desvantagem de ser necessário ter o conhecimento prévio da seqüência que se pretende estudar. Realizamos a PCR em duas etapas, por isso denominada PCRnested, na qual trabalhamos com dois pares de oligonucleotídeos, um que corresponde ao gene AMGX da amelogenina localizado no cromossomo $\mathrm{X}$ e o outro ao pseudogene da amelogenina localizado no cromossomo $\mathrm{Y}$. 
A taxa de sucesso da PCR em amostras com falha de crescimento foi elevada $(28 / 32,87,5 \%)$. Não encontramos na literatura trabalhos que avaliassem o sexo fetal em material de aborto usando a PCR-nested.

Em conclusão, este estudo evidenciou que em $80-90 \%$ das amostras de abortamentos espontâneo encaminhadas, foi possivel determinar-se o cariótipo por meio do estudo citogenético, da FISH e da PCR. As técnicas de FISH e PCR foram importantes nos casos sem resultado no estudo citogenético (devido à falha de crescimento celular): permitiram a obtenção de resultado em mais de $80 \%$ desses casos. A concordância dos resultados entre os três exames reforça o valor e confiabilidade das técnicas de biologia molecular como auxiliares da citogenética para o estudo do cariótipo em material de abortamento. Assim como apontado na literatura, a taxa de anomalias cromossômicas em casos de abortamentos espontâneos é elevada em nosso meio.

\section{Referências}

1. Borgaonkar DS. Chromosomal variation in man: a catalog of chromosomal variants and anomalies 5 th ed. New York: Wiley-Liss; 1989. p. 138-57.

2. Kalousek DK. Clinical significance of morphologic and genetic examination of spontaneously aborted embryos. Am J Reprod Immunol. 1998;39(2):108-19.

3. Van Lijnschoten G, Arends JW, De la Fuente AA, Schouten HJ, Geraedts JP. Intra and inter-observer variation in the interpretation of histological features suggesting chromosomal abnormality in early abortion specimens. Histophatology. 1993;22(1):25-9.

4. Simoni G, Brambati SB, Danesino C, Rossella F, Terzoli GL, Ferrari M, et al. Efficient direct chromosome analysis and enzyme determinations from chorionic villi samples in the first trimester of pregnancy. Hum Genet. 1983;63(4):349-57.

5. Kalousek DK. Anatomic and chromosome anomalies in specimens of early spontaneous abortions: seven-year experience. Birth Defects Orig Artic Ser. 1987;23(1):153-68.

6. Qumsiyeh MB. Chromosome abnormalities in the placenta and spontaneous abortions. J Matern Fetal Med. 1998;7(4):210-2.

7. Goddijn M, Leschot NJ. Genetic aspects of miscarriage. Baillieres Best Pract Res Clin Obstet Gynaecol. 2000;14(5):855-65.

8. Carp H, Toder V, Aviram A, Daniely M, Mashiach S, Barkai G. Karyotype of the abortus in recurrent miscarriage. Fertil Steril. 2001;75(4):678-82.

9. Stephenson MD, Awartani KA, Robinson WP. Cytogenetic anlysis of miscarriages from couples with recurrent miscarriage: a case-control study. Hum Reprod. 2002;17(2):446-51.

10. Kalousek DK, Dimmick JE. Pathology of spontaneous abortions and chromosomal abnormalities in stillbirth and neonatal death. In: Dimmick JE, Kalousek DK, editors. Developmental pathology of the embryo and fetus. Philadelphia: JB Lippincott; 1992. p. 55-110.

11. Cavalcanti DP, Ferrari I, Pinto W Jr. Chromosome analysis of 52 spontaneous abortuses in Brazil. Rev Bras Genet. 1988;11(1):149-54.

12. Moraes AC, Hashimoto EM. Estudo cromossômico de restos ovulares. In: Moron AF, editor. Medicina fetal na prática obstétrica. São Paulo: Ed. Santos; 2003. p. 117-122.

13. Salafia C, Maier D, Vogel C, Pezzullo J, Burns J, Silberman L. Placental and decidual histology in spontaneous abortion: detailed description and correlations with chromosome number. Obstet Gynecol. 1993;82(2):295-303.

14.Eiben B, Trawicki W, Hammans W, Goebel R, Pruggmayer M, Epplen JT. Rapid prenatal diagnosis of aneuploidies in uncultured amniocytes by fluorescence in situ hybridization. Evaluation of > 3,000 cases. Fetal Diagn Ther. 1999;14(4):193-7.

15. Jobanputra V, Roy KK, Kriplani A, Kucheria K. Prenatal diagnosis of chromosomal abnormalities in women with high risk pregnancies. Indian J Med Res. 2001;114:148-55.

16.Jobanputra V, Roy KK, Kucheria K. Prenatal detection of aneuploidies using fluorescent in situ hybridization: a preliminary experience in an Indian set up. J Biosci. 2002;27(2):155-63.

17. Schaaff F, Wedemann H, Schwinger E. Analysis of sex and D F508 in single amniocytes using primer extension pre-amplification. Hum Genet. 1996;98(2):158-61.

18. Lim HN, Berkovitz GD, Hughes IA, Hawkins JR. Mutation analysis of subjects with 46,XX sex reversal and 46,XY gonadal dysgenesis does not support the involvement of SOX3 in testis determination. Hum Genet. 2000;107(6):650-2.

19. Kajii T, Ferrier A, Niikawa N, Takaraha H, Ohama $\mathrm{K}$, Avirachan S. Anatomic and chromosomal anomalies in 639 spontaneous abortuses. Hum Genet. 1980;55(1):87-98.

20.Van Lijnschoten G, Arends JW, Geraedts JP. Comparison of histological features in early spontaneous and induced trisomic abortions. Placenta. 1994;15(7):765-73.

21. Ohno M, Maeda T, Matsunobu A. A cytogenetic study of spontaneous abortions with direct analysis of chorionic villi. Obstet Gynecol. 1991;77(3):394-8.

22. Paradinas FJ, Browne P, Fisher RA, Foskett M, Bagshae KD, Newlands E. A clinical, histophatological and flow cytometric study of 149 complete moles, 146 partial moles and 107 nonmolar hydropic abortions. Histophatology. 1996;28(2):101-10. 